\title{
Effect of Lesion Age, Humidity, and Fungicide Application on Sporulation of Alternaria alternata, the Cause of Brown Spot of Tangerine
}

\author{
R. F. Reis and A. de Goes, São Paulo State University, Jaboticabal, São Paulo, Brazil; S. N. Mondal and T. Shilts, \\ University of Florida, Citrus Research and Education Center, Lake Alfred 33850; F. C. Brentu, University of Ghana, \\ Accra; and L. W. Timmer, University of Florida, Citrus Research and Education Center, Department of Plant Pa- \\ thology, Lake Alfred 33850
}

\begin{abstract}
Reis, R. F., de Goes, A., Mondal, S. N., Shilts, T., Brentu, F. C., and Timmer, L. W. 2006. Effect of lesion age, humidity, and fungicide application on sporulation of Alternaria alternata, the cause of brown spot of tangerine. Plant Dis. 90:1051-1054.

Alternaria brown spot, caused by Alternaria alternata, causes yield losses and fruit blemishes on many tangerines and their hybrids in most citrus areas of the world where susceptible cultivars are grown. Although the conditions affecting infection and disease severity are known, little information is available on inoculum production on infected tissue. We found that sporulation on leaves began about 10 days after symptoms developed, was abundant from 20 to 40 days, and declined thereafter. Conidial production was far greater on leaf than on fruit or twig lesions. Spore production per unit area of leaf lesion was greater on the more susceptible hybrids, Minneola and Orlando tangelos, than on the less susceptible Murcott tangor. At 74\% relative humidity, conidial production on leaf lesions was low, but it was abundant at $85,92.5,96$, and $100 \%$. Application of $\mathrm{Q}_{\mathrm{o}} \mathrm{I}$ or copper fungicides, but not ferbam, suppressed sporulation on leaf lesions for about 14 to 21 days after application. Additional applications did not appear to be more effective than a single spray in reducing inoculum production.
\end{abstract}

Alternaria brown spot (ABS) produces black necrotic lesions on leaves, twigs, and fruit of tangerines and their hybrids $(18,21)$. Lesions appear 2 to 3 days after infection and expand rapidly due to production of a host-specific toxin. Severe infection results in extensive leaf and fruit drop and twig dieback. On remaining fruit, lesions vary from small, black necrotic spots to large sunken pockmarks, thus reducing the value of the fruit for the fresh market. Worldwide distribution of the pathogen has expanded greatly in recent years. ABS is a serious problem in semiarid as well as in humid citrus-producing areas (18).

The causal agent of ABS was originally designated as Alternaria citri Ellis \& Pierce (9). More recently, Solel (13) considered it to be a pathovar of A. alternata and designated it as A. alternata (Fr.:Fr.) Keissl. pv. citri. Others have found what they consider to be species-level morphological and biochemical differences among

Corresponding author: L. W. Timmer

E-mail: lwt@crec.ifas.ufl.edu

This research was partially funded by the Florida Citrus Production Advisory Council Project No. 043-07P, and by Fundação Coordenação de Aperfeiçamento de Pessoal de Nível Superior (CAPES).

Accepted for publication 30 March 2006.

DOI: 10.1094/PD-90-1051

(C) 2006 The American Phytopathological Society isolates of the tangerine pathotype $(1,12)$ and have designated 10 species of Alternaria among isolates pathogenic to tangerine (12). Our molecular phylogenetic studies indicate that all of the small-spored Alternaria isolates from citrus are closely related $(7,8)$. We consider them to be $A$. alternata and use that species designation in this article.

The disease cycle of $A$. alternata is relatively simple $(18,21)$. Conidia produced on symptomatic tissue are dispersed aerially and deposited on plant surfaces where they germinate and infect susceptible tissue when available, usually from March to November. Conidial release is triggered by sudden drops in relative humidity or by rainfall events (20). In previous studies (5), we found that the optimum temperature for infection was 23 to $27^{\circ} \mathrm{C}$ and that 4 to $8 \mathrm{~h}$ of leaf wetness was sufficient for limited infection, but $12 \mathrm{~h}$ or more resulted in a higher disease incidence. In field studies, we found that the conditions that favored infection were: (i) rainfall greater than 2.5 $\mathrm{mm}$, (ii) leaf wetness duration greater than $10 \mathrm{~h}$, and (iii) average daily temperatures between 20 and $28^{\circ} \mathrm{C}$ (15). This information was used to develop a predictive model, the Alter-Rater, to assist in timing of fungicide applications $(3,10,16,17)$.

Sporulation of Alternaria spp. in culture has been studied extensively, but information on conidial production on host tissue is more limited $(11,14)$. Since Alternaria spp. are necrotrophic, sporulation is greatest on tissues recently killed by the patho- gen. In previous preliminary studies, we found that the tangerine pathotype of $A$. alternata sporulated best when infected leaves were moist or held at high humidity, but produced no conidia on infected leaves held at 50 to $70 \%$ relative humidity (20). Whiteside (23) noted that sporulation was more abundant on diseased shoots than on fruit and felt that the fungus overwintered on diseased shoots, which provided the primary inoculum in the spring.

In most groves of susceptible cultivars in Florida, inoculum levels are high and conidial numbers were not a limiting factor in infection. In earlier field studies, the number of conidia trapped was not related to the amount of infection (17) and had no value in predicting infections or the need for fungicide applications. Rain events increased infection, but probably also washed airborne conidia from the atmosphere and reduced the number trapped (17). However, a better understanding of the temporal and spatial aspects of conidial production may allow modifications in cultural and disease management strategies that would reduce inoculum levels and facilitate control. The objective of this study was to evaluate the effects of type of plant organ, lesion age, cultivar, relative humidity, and fungicide application on conidial production.

\section{MATERIALS AND METHODS}

General methods. All inoculations were conducted using isolate EV-31s of the tangerine pathotype of $A$. alternata originally recovered from a leaf of Minneola tangelo (Citrus paradisi $\times$ C. reticulata) (6). Conidia were produced in culture as described previously (5). New shoots were spray-inoculated with a suspension of about $10^{4}$ conidia per $\mathrm{ml}$, covered with a plastic bag, and placed in a mist bed for 14 to $16 \mathrm{~h}$ at 22 to $28^{\circ} \mathrm{C}$.

For measurement of sporulation, 4-mmdiameter disks were cut from the tissue bearing lesions of Alternaria brown spot. Leaf disks bearing a single lesion were placed on a moist filter paper in petri dishes and incubated with $12 \mathrm{~h}$ per day of fluorescent light at 23 to $25^{\circ} \mathrm{C}$ for $48 \mathrm{~h}$. Unless otherwise noted, 10 disks for each of four replicate samples were placed in $0.5 \mathrm{ml}$ of water, vortexed, and the conidial concentration determined by counting all conidia recovered in $0.2 \mathrm{ml}$ on a micro- 
scope slide. The area of the lesion was calculated from the radius, which was measured with a caliper, and the conidial counts were expressed as the number of conidia per $\mathrm{mm}^{2}$ of lesion area.

Effect of organ type and cultivar on sporulation. Mature trees of Minneola and Orlando tangelo $(C$. paradisi $\times C$. reticulata) and Murcott tangor (probable $C$. sinensis $\times C$. reticulata hybrid) were selected in groves at the University of Florida, CREC, for this study. Leaves, twigs, and fruit were monitored for symptom appearance, and samples were collected at 10-day intervals beginning 10 days after symptom appearance. Sporulation was determined as indicated above except that only five lesions per sample were used for the fruit and twig lesions.

Effect of leaf age on sporulation. Lesions from Minneola tangelo leaves from inoculated plants in the greenhouse and from shoots on mature trees in the field were sampled beginning 10 days after symptom appearance. Sporulation was measured as described above at 10-day intervals for 2 months.

Recently matured symptomatic leaves were collected from mature Minneola tangelo trees to determine the amount and duration of sporulation on abscised leaves on the grove floor. Four replicate samples of 20 leaves each were placed in mesh bags and located beneath the trees in the field. Five to seven leaf disks were col-
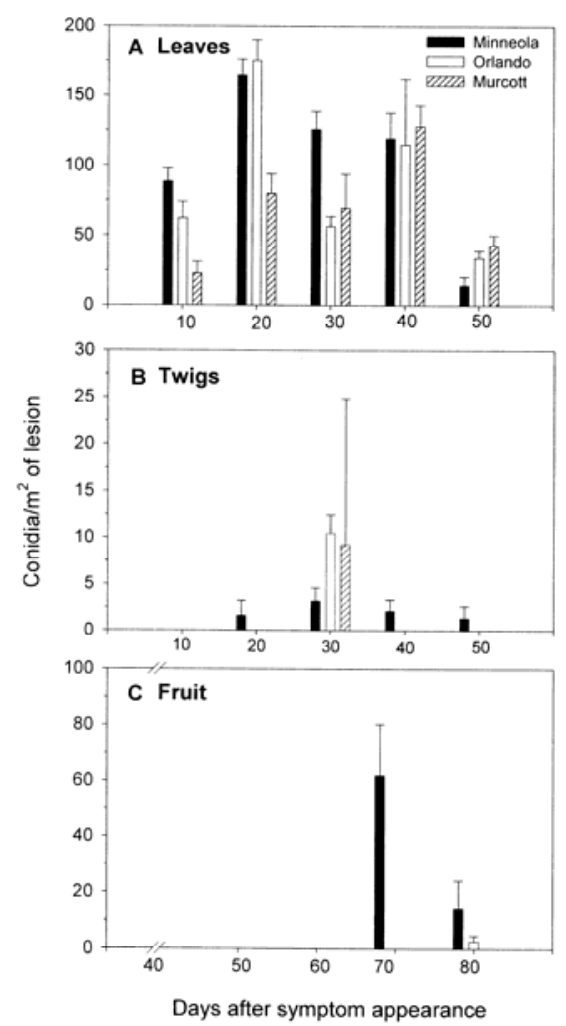

Fig. 1. Conidial production of Alternaria alternata on brown spot lesions on different tissue of field trees of Minneola and Orlando tangelos and Murcott tangors with time after symptom appearance. A, leaves, $\mathbf{B}$, twigs, and $\mathbf{C}$, fruit. lected from each bag at 4-day intervals for 2 weeks and sporulation determined as described above.

Effect of relative humidity on sporulation. To determine the effect of relative humidity on sporulation, closed desiccators were set up with salt and sucrose solutions to create different relative humidities. Saturated solutions of $\mathrm{NaNO}_{3}$, sucrose, $\mathrm{KNO}_{3}$, $\mathrm{KH}_{2} \mathrm{PO}_{4}$, as well as distilled water, were used to create relative humidities of 74.0, 85.0, 92.5, 96.0, and 100\%, respectively (24). Humidities in the chambers were verified by a Ratio Signal Remote Thermometer (Fisher Scientific, Pittsburg, PA). Chambers were maintained at $25^{\circ} \mathrm{C}$. Inoculated leaves of Minneola tangelo (20 to 30 days old) were used as a source of lesions. Four replicate sets of 10 lesions each were placed in the chambers for $48 \mathrm{~h}$ and conidial numbers determined as described above.

Effect of fungicide application on sporulation. In the first experiment, fungicides were applied to runoff on branches of mature, symptomatic Minneola tangelo trees in the field with a 10-liter hand pressurized sprayer to determine the effect of these products on sporulation. Pyraclostrobin was applied as Headline at $0.25 \mathrm{~g}$ a.i./liter, trifloxystrobin was applied as Gem at $0.125 \mathrm{~g}$ a.i./liter, azoxystrobin was applied as Abound at $0.19 \mathrm{~g} /$ liter, ferbam was applied as Ferbam Granuflo at $9.1 \mathrm{~g}$ a.i./liter, and copper hydroxide was applied as Kocide 2000 at $1.4 \mathrm{~g}$ of metallic copper per liter. One day after application, four replicate samples of 10 lesions each were collected arbitrarily from leaves on the treated branches as well as from an equal number of nonsprayed controls.

In the second experiment, the effect of a single application of selected fungicides on subsequent sporulation was assessed. Two mature Minneola tangelo trees were sprayed to runoff with a high pressure sprayer with pyraclostrobin and copper hydroxide at the above rates, and two were left nonsprayed. Four replicate samples of 10 lesions each were collected arbitrarily from each treatment at $1,7,14$, and 21 days after spraying. Conidial numbers were determined as described above.

In two other experiments, the effect of multiple applications of fungicide on sporulation under field and greenhouse conditions was determined. In the field, sprays were applied to 25- to 30-day-old lesions as above using pyraclostrobin, azoxystrobin, and copper hydroxide at the above rates. Sporulation was assessed as described above at 7, 15, and 28 days after applications on treated leaves and on nonsprayed control leaves. Additional fungicide sprays at the same rates were made after 7 and 15 days immediately following sample collection. In the greenhouse, Minneola tangelo trees with 20- to 25-day-old lesions on mature leaves were sprayed to runoff with the same fungicides and rates using a hand sprayer. Lesions were col- lected and sporulation determined as described above on sprayed and nonsprayed controls. As in the field experiment, applications were repeated after sampling on days 7 and 15 after the first spray.

Statistical analysis. The effects of various factors were compared by analysis of variance. All conidial numbers were transformed to the $\log _{10}$ prior to analysis to normalize the variances. For each experiment, the variances of measurements in the two separate runs of each experiment were shown to be equal using the Bartlett's twotailed $F$ test. Thus, data from each of the two experiments were pooled. Mean separations were conducted using the WallerDuncan $k$-ratio $t$ test, $P \leq 0.05$. In some instances, curve-fitting was conducted to determine the relationship of time after leaf abscission or relative humidity to conidial production. All analyses were conducted using SAS Version 8.2 (SAS Institute, Cary, NC).

\section{RESULTS}

Effect of plant organ, lesion age, and cultivar. Sporulation was much greater on leaf lesions than on lesions on fruit or twigs (Fig. 1). Conidial production did not begin until leaf lesions were about 10 days old. Sporulation was very high from 20 to 40 days after lesion appearance on all three cultivars, but declined to low levels by 50 days after lesion formation. The greatest conidial production on twigs occurred about 30 days after symptom development. No conidial production was observed on fruit lesions until 70 days after symptoms developed, but by 80 days, sporulation had declined considerably.

The analysis of variance indicated that cultivar had a significant effect on sporulation on leaves. Conidial production was greatest on Minneola and Orlando tangelos, and lower on the less susceptible Murcott tangor (Fig. 1A). There were too few conidia produced on fruit or twig lesions to conduct statistical analyses. However, except for twigs at 30 days after lesion development, nearly all of the conidia were observed on lesions of Minneola tangelo, the most susceptible cultivar (Fig. 1B). A few conidia were produced on fruit of Orlando tangelo after 80 days (Fig. 1C).

In other experiments, the effect of lesion age on Minneola tangelo was assessed in the field and greenhouse. In the field, sporulation did not begin until 2 weeks after lesion formation (Fig. 2). Conidial production peaked from 20 to 40 days after lesion formation and then declined. In the greenhouse, where leaves were dry for the entire period after inoculation, sporulation did not begin until 20 days after symptom appearance. As in the field, sporulation was greatest from 20 to 40 days after symptom appearance and declined thereafter.

Sporulation on symptomatic leaves placed on the grove floor was very high initially and 4 days after placement (Fig. 
3). However, by 8 days after placement, sporulation was minimal and was virtually zero by 12 days thereafter.

Effect of relative humidity. The number of conidia produced was low at $74 \%$

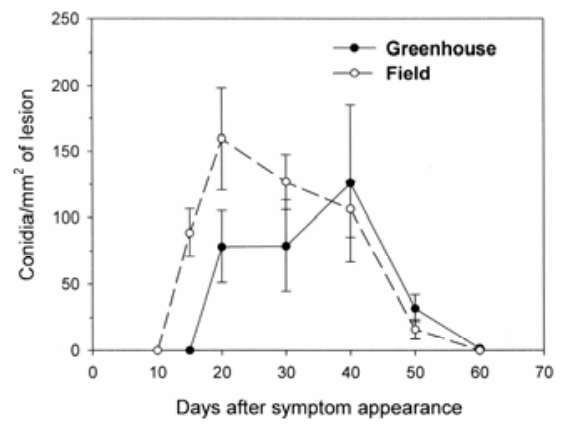

Fig. 2. Effect of lesion age on conidial production of Alternaria alternata on brown spot lesions on Minneola tangelo in the field and greenhouse.

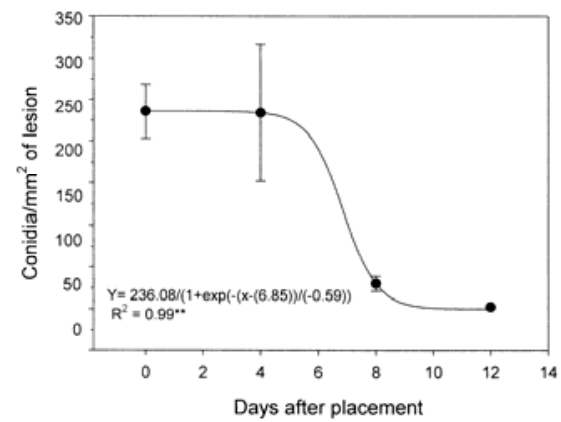

Fig. 3. Effect of time after placement of detached, symptomatic Minneola tangelo leaves on the grove floor on conidial production of Alternaria alternata on brown spot lesions. ** = significant at $P \leq 0.01$.
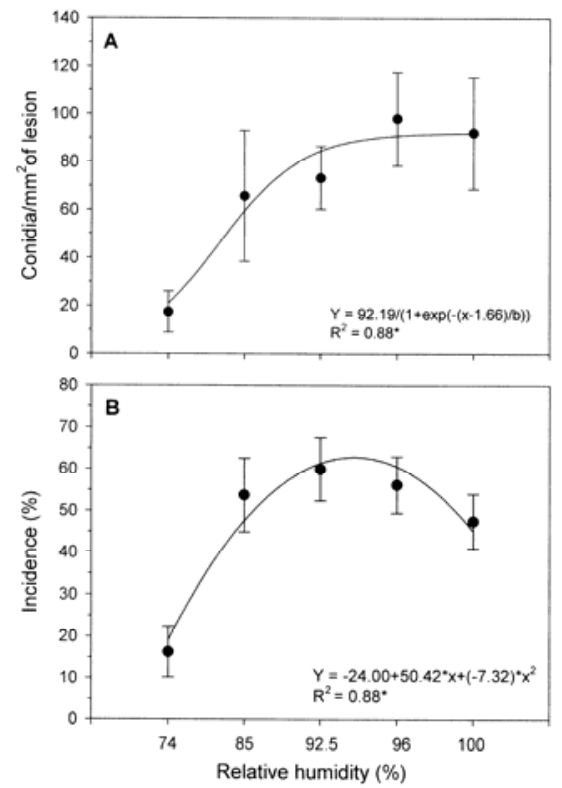

Fig. 4. Effect of relative humidity on A, sporulation of Alternaria alternata on brown spot lesions, and $\mathbf{B}$, percentage of lesions with conidia present on Minneola tangelo. $*=$ significant at $P \leq 0.05$.
$\mathrm{RH}$ and greater at $85 \% \mathrm{RH}$ and above (Fig. $4 \mathrm{~A})$. The percentage of lesions producing conidia was very low at $74 \% \mathrm{RH}$, increased at higher relative humidities, and declined slightly at $100 \%$ RH (Fig. 4B).

Effect of fungicide application. In the initial experiment, the $\mathrm{Q}_{\mathrm{O}} \mathrm{I}$ fungicides pyraclostrobin, trifloxystrobin, and azoxystrobin, as well as copper hydroxide, substantially reduced sporulation 1 day after application (Table 1). There were no significant differences among those treatments. Ferbam application failed to reduce conidial production significantly.

In subsequent experiments, the effects of single applications of the $\mathrm{Q}_{0} \mathrm{I}$ fungicide pyraclostrobin and copper hydroxide were assessed. In the field experiments where a single fungicide spray was applied, sporulation was reduced by both fungicides at 1 , 7,14 , and 21 days after spraying (Fig. 5). Only on one date was there a significant difference between the two fungicides.

In other experiments in the greenhouse and field, the effect of two $\mathrm{Q}_{0} \mathrm{I}$ fungicides, azoxystrobin and pyraclostrobin, and copper hydroxide on sporulation was measured with multiple applications. In the greenhouse experiment, copper hydroxide had no significant effect on sporulation at 7 or 14 days after the first application but did reduce sporulation slightly at 28 days (Fig. 6A). Both $\mathrm{Q}_{0} \mathrm{I}$ fungicides reduced sporulation at 7 and 14 days after the first application, but only pyraclostrobin reduced sporulation after 28 days. By 28 days, conidial production in the control was very low. In the field, all three fungicides reduced conidial production 7 and 14 days after the first spray, but not at 28 days (Fig. 6B). Conidial production was low after 14 and 28 days even in the control.

\section{DISCUSSION}

Other than a few limited observations (23), there is very little information available on the conditions affecting sporulation of A. alternata or the duration of conidial production on lesions on citrus tissue. As with other Alternaria spp. $(11,14)$, A. alternata on citrus is a necrotroph and produces necrotic lesions on leaves, twigs, and fruit by production of a host-specific toxin (18). We found that sporulation began about 10 days after symptoms formed on leaves and continued for about the next 40 days. By about 60 days after symptom appearance, conidia were no longer produced.

Whiteside (23) noted that sporulation was more abundant on leaves than on fruit. His observations indicated that most of the infected leaves dropped before winter, and he felt the pathogen overwintered primarily on twigs. We observed many infected leaves, twigs, and fruit on trees during winter. Despite the fact that our results show little sporulation 60 days after lesion development, lesions may be able to produce a few conidia that would serve as primary inoculum in the spring. Lesions on fruit appear to require more time to produce conidia. Most tangerines and their hybrids are harvested in late fall or early winter, thus removing most fruit inoculum sources. However, late-maturing hybrids such as Murcotts and offbloom fruit of other cultivars also could serve as a source of primary inoculum.

No comparative studies have been conducted to measure sporulation on organs of different cultivars. However, lesions on Minneola and Orlando tangelos are much larger than those on less susceptible hybrids such as Murcott (21). Thus, it might be expected that more conidia would be produced in groves of highly susceptible cultivars than of more tolerant ones. Moreover, we demonstrated here that conidial production on more susceptible cultivars is also greater per unit area of leaf lesion.

In earlier studies, we found that conidial production was greatest when leaves with lesions were maintained slightly moist or held at high humidity (20). Alternaria spp. are known to thrive under semiarid conditions (11), and brown spot is a serious problem in semiarid citrus areas $(15,18)$. In the current study, we found that sporulation was abundant at $85 \% \mathrm{RH}$ and above. There was an indication in the previous study (20) and in the current one that the presence of free water on the leaves is not conducive to conidial production.

A possible problem in monitoring sporulation is the presence of saprophytic $A$. alternata that are widely present in citrus groves (18). In this study, conidiophores were observed to emerge directly from the lesion area, thus making it less likely that they were saprophytes. In a previous study of cultures from airborne conidia in a grove with brown spot, we found that less than $1 \%$ of the isolates were nonpathogenic (20). Thus, most of the conidia

Table 1. Effect of fungicides on sporulation of Alternaria alternata on brown spot lesions on Minneola tangelo 1 day after application

\begin{tabular}{|c|c|c|}
\hline Fungicide & Rate (g a.i./liter) & Conidia/mm $/ \mathrm{mm}^{2}$ of lesion \\
\hline Control & $\ldots$ & $40.5 \mathrm{a}^{\mathrm{z}}$ \\
\hline Pyraclostrobin & 0.25 & $4.1 \mathrm{~b}$ \\
\hline Trifloxystrobin & 0.125 & $3.6 \mathrm{~b}$ \\
\hline Azoxystrobin & 0.19 & $5.8 \mathrm{~b}$ \\
\hline Ferbam & 9.1 & $22.2 \mathrm{a}$ \\
\hline Copper hydroxide & 1.4 & $5.4 \mathrm{~b}$ \\
\hline
\end{tabular}

${ }^{\mathrm{z}}$ Mean separation by the Waller-Duncan $k$-ratio $t$ test, $P=0.05$. Average of two experiments. 


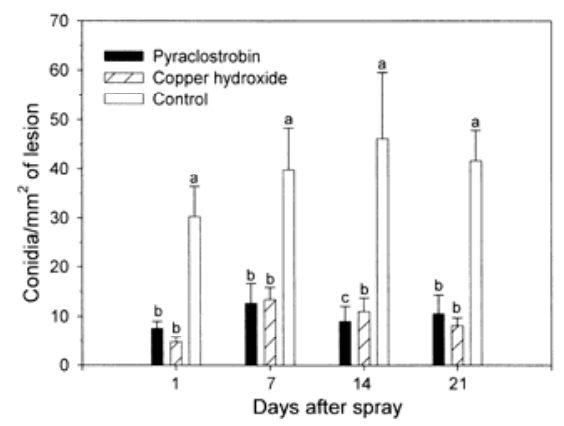

Fig. 5. Effect of time after a single application of fungicide on day zero on conidial production of Alternaria alternata on brown spot lesions on Minneola tangelo in the field.

measured in this study were most likely produced by pathogenic isolates, although we cannot eliminate the possibility that a few were from saprophytes.

Fungicides that are currently recommended for control of ABS in Florida are copper products and the $\mathrm{Q}_{\mathrm{O}} \mathrm{I}$ fungicides, as well as ferbam and neem oil under certain circumstances (19). Copper fungicides and the $\mathrm{Q}_{\mathrm{o}} \mathrm{I}$ fungicides are highly effective in preventing infection and reducing disease incidence $(10,15,22)$. However, their effectiveness in reducing inoculum production of ABS was unknown. The ability of $\mathrm{Q}_{0} \mathrm{I}$ fungicides to reduce sporulation of other fungi on citrus (4) and on many other crops is well-established $(2,25)$. Based on the current research, it appears that the $\mathrm{Q}_{0} \mathrm{I}$ fungicides, and except in one experiment, copper products, substantially inhibit sporulation of A. alternata, thus reducing disease pressure.

Multiple sprays applied to the same lesion did not appear to have a greater effect on sporulation than a single spray, although they were not compared directly on the same experiment. However, subsequent sprays would reduce sporulation on newly formed lesions. In practice, groves may require monthly to weekly applications from the first leaf flush in the spring till midsummer depending on the cultivar and the disease history in the grove $(3,10,19)$. In the development of the Alter-Rater predictive model $(16,17)$, we were unable to relate counts of airborne conidia to disease incidence. Thus, in heavily infested groves, inoculum is probably in excess and weather factors are the primary determinants of disease incidence and severity.

Cultural measures such as wider spacing to improve air circulation and planting of susceptible cultivars on sites with good air drainage (19) not only may help reduce infection, but also may reduce inoculum production by decreasing the duration of wetting periods. Copper and $\mathrm{Q}_{0} \mathrm{I}$ fungicides reduce inoculum by reducing lesion formation, but also reduce inoculum pro-

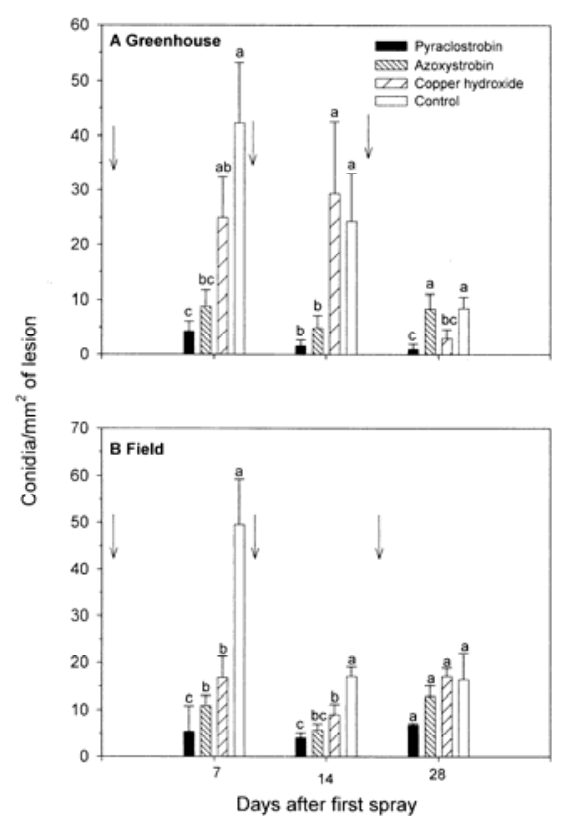

Fig. 6. Effect of application of fungicide at 0, 7, and 14 days on conidial production of Alternaria alternata on brown spot lesions at 7, 14, and 28 days after the first application in $\mathbf{A}$, the greenhouse, and $\mathbf{B}$, the field. Arrows indicate timing of fungicide applications.

duction directly on existing lesions. Harvesting of fruit prior to the spring flush of growth may help reduce primary inoculum. Planting of groves with wider spacing to improve air circulation and fungicide applications on foliage may serve to reduce disease pressure on fruit.

\section{LITERATURE CITED}

1. Anderson, B., Hansen, M. E., and Smedsgaard, J. 2005. Automated and unbiased image analysis as tools in phenotype classification of small-spored Alternaria spp. Phytopathology 95:1021-1029.

2. Bartlett, D. W., Clough, J. M., Godwin, J. R., Hall, A. A., Hamer, M., and Parr-Dobrzanski, B. 2002. The strobilurin fungicides. Pest Manag. Sci. 58:649:662.

3. Bhatia, A., Roberts, P. D., and Timmer, L. W. 2003. Evaluation of the Alter-Rater model for timing of fungicide applications for control of Alternaria brown spot of citrus. Plant Dis. 87:1089-1093.

4. Bushong, P. M., and Timmer, L. W. 2000. Evaluation of postinfection control of citrus scab and melanose with benomyl, fenbuconazole, and azoxystrobin. Plant Dis. 84:12461249.

5. Canihos, Y., Peever, T. L., and Timmer, L. W. 1999. Temperature, leaf wetness, and isolate effects on infection of Minneola tangelo leaves by Alternaria sp. Plant Dis. 83:429-433.

6. Peever, T. L., Canihos, Y., Olsen, L., Ibáñez, A., Liu, Y.-C., and Timmer, L. W. 1999. Population genetic structure and host specificity of Alternaria spp. causing brown spot of Minneola tangelo and rough lemon in Florida. Phytopathology 89:851-860.

7. Peever, T. L., Carpenter-Boggs, L., Timmer, L. W., Carris, L. M., and Bhatia, A. 2005. Citrus black rot is caused by phylogenetically distinct lineages of Alternaria alternata. Phytopathol- ogy 95:512-518.

8. Peever, T. L., Su, G., Carpenter-Boggs, L., and Timmer, L. W. 2004. Molecular systematics of citrus-associated Alternaria spp. Mycologia 96:119-134

9. Pegg, K. G. 1966. Studies of a strain of Alternaria citri Pierce, the causal agent of brown spot of Emperor mandarin. Qld. J. Agric. Anim. Sci. 23:14-18.

10. Peres, N. A., and Timmer, L. W. Alternaria brown spot of citrus in Brazil: Evaluation of the Alter-Rater for spray timing and effects on yield of Murcott tangor. Crop Prot. 25:454 460.

11. Rotem, J. 1994. The Genus Alternaria: Biology, Epidemiology, and Pathogenicity. American Phytopathological Society, St. Paul, MN.

12. Simmons, E. G. 1999. Alternaria themes and variations (226-235): Classification of citrus pathogens. Mycotaxon 70:263-323.

13. Solel, Z. 1991. Alternaria brown spot on Minneola tangelos in Israel. Plant Pathol. 40:145 147.

14. Strandberg, J. O. 1992. Alternaria species that attack vegetable crops: Biology and options for disease management. Pages 175-208 in: Alternaria: Biology. Plant Diseases and Metabolites. J. Chelkowski and A. Visconti, eds. Elsevier, Amsterdam.

15. Timmer, L. W. 2000. Evaluation of fungicides for control of Alternaria brown spot of citrus, 1998. Fungic. Nematicide Tests 55:570.

16. Timmer, L. W., Darhower, H. M., and Bhatia, A. 2001. The Alter-Rater, a new weather-based model for timing fungicide sprays for Alternaria control. Publ. No. SP-175. University of Florida, IFAS, EDIS, Gainesville.

17. Timmer, L. W., Darhower, H. M., Zitko, S. E., Peever, T. L., Ibáñez, A. M., and Bushong, P. M. 2000. Environmental factors affecting the severity of Alternaria brown spot of citrus and their potential use in timing fungicide applications. Plant Dis. 84:638-643.

18. Timmer, L. W., Peever, T. L., Solel, Z., and Akimitsu, K. 2003. Alternaria diseases of citrus-Novel pathosystems. Phytopathol. Mediterr. 42:99-112.

19. Timmer, L. W., Rogers, M. E., and Buker, R. S., eds. 2005. 2005 Florida Citrus Pest Management Guide. Univ. Fl., Inst. Food Agric. Sci., Publ. No. SP-43.

20. Timmer, L. W., Solel, Z., Gottwald, T. R., Ibáñez, A. M., and Zitko, S. E. 1998. Environmental factors affecting production, release, and field populations of conidia of Alternaria alternata, the cause of brown spot of citrus. Phytopathology 88:1218-1223.

21. Timmer, L. W., Solel, Z., and Orozco-Santos, M. 2000. Alternaria brown spot of mandarins. Pages 19-20 in: Compendium of Citrus Diseases, 2nd ed. L. W. Timmer, S. M. Garnsey, and J. H. Graham, eds. American Phytopathological Society, St. Paul, MN.

22. Timmer, L. W., and Zitko, S. E. 1999. Evaluation of fungicides for control of Alternaria brown spot, 1997. Fungic. Nematicide Tests 54:555.

23. Whiteside, J. O. 1988. Alternaria brown spot of mandarins. Page 8 in: Compendium of Citrus Diseases. J. O. Whiteside, S. M. Garnsey, and L. W. Timmer, eds. American Phytopathological Society, St. Paul, MN

24. Winston, P. W., and Bates, D. H. 1960. Saturated solutions for control of humidity in biological research. Ecology 41:232-237.

25. Ypema, H. L., and Gold, R. E. 1999 Kresoxim-methyl: Modification of a naturally occurring compound to produce a new fungicide. Plant Dis. 83:4-19. 